\title{
STRAIN IN THE UPSETTING PROCESS
}

\section{INTRODUCTION}

Upsetting is an technological operation of open die forging, which is performed in order to reduce the height - in the direction of action of a forging hammer or press, with simultaneous increase in its cross-sectional dimensions [5]. The operation of upsetting is carried out if: cross-section of finished part is larger than that of forging stock, required degree of working calls for increasing initial dimensions of ingot prior to main operations (usually, cogging), ingot is prepared to punching a hole, forging in shapes of blocks, discs, rings etc., or improvement of mechanical properties of forging is necessary. Cylindrical billet gains a form of a barrel. Average diameter at any stage of upsetting can be approximately calculated based on constant volume condition

$$
d=d_{0} \sqrt{\frac{h_{0}}{h}}
$$

where:

$d_{0}, h_{0}$ - diameter and height before upsetting,

$d, h$ - diameter and height after upsetting.

Proper conduct of upsetting requires [5] that initial height to diameter ratio should not exceed $2.5\left(h_{0} / d_{0} \leq 2.5\right)$, and while upsetting cuboid, the height to shorter wall of the base ratio should be less than 3.5. If this value is exceeded, a bulging can occur, which requires additional operations to be removed. Forged billet needs uniform heating in the bulk for the maximum forging temperature. Before upsetting, the ingot should be forged into round

* Ph.D.: Faculty of Metals Engineering and Industrial Computer Science, AGH University of Science and Technology, Krakow, Poland; kajtoch@metal.agh.edu.pl 
cross-section. Degrees of deformation during each blow of the hammer or press should be appropriately determined so as to exceed critical strain value. Surface must be free of defects and head surfaces that remain in contact with dies, parallel to the tools.

Upsetting should be realized with strong blows of hammers or press [5]. When the energy of a blow or pressure of the ram is too low, concave shape of the free surface is observed. Upsetting on a hydraulic press is carried out with a use of flat dies or special types of plates, in case of large ingots. If the ingot is thereby prepared for subsequent cogging, the bottom toll has an orifice to house the manipulating journal. To ensure convenient stress distribution concave dies are sometimes used. When forging rings or discs for gears, flanges or other axi-symmetrical complex-shape parts, upsetting in special rings is performed. This method allows simultaneous increase in diameter and forming the hubs.

After upsetting the side surface becomes distorted $[1,4,5]$. Its profile and character of deformation depends on frictional conditions and initial dimensions ratio $h_{0} / d_{0}$. In upsetting in flat dies (with $\mu \neq 0$ ) of cylindrical billet of slenderness $h_{0} / d_{0}>2$ in the beginning of the process on both ends of the billet in the free surface two bulges are formed, which smoothly turn into central cylindrical surface. With continuation of the process the cylindrical surface in gaining width and eventually, the billet gains a form of a barrel. When the slenderness ratio is low $\left(h_{0} / d_{0}<2\right)$, the billet takes on the barrel form with the commence of the process.

\section{COMPRESSION CURVES}

The form of the curves in the range of stresses: engineering $-\sigma_{c}=f\left(-\varepsilon_{c}\right)$ or logarithmic $-\sigma_{r z}=f\left(-q_{c}\right)$ is dependent on numerous technological parameters, of which the most important are $[3,4]$ :

1 - mechanical properties, such as ductility and strength of the tested material,

2 - aspect ratio $h_{0} / d_{0}$ (where: $h_{0}, d_{0}$ - initial height and diameter) of the compressed specimen,

3 - value of friction coefficient in the surface of the platens,

4 - relative height reduction after upsetting.

The influence of the first group of the parameters is clearly visible in the compression curves (Fig. 1a). For ductile materials of low strength, such as lead, aluminum, zinc, copper or low carbon steel, the ends of the curves are points where the test was broken. Determination of compression strength of elasto-plastic materials is practically impossible. In case of brittle materials, such as cast iron, the test is stopped the moment the fracture forms in the specimen, which determines its compression ultimate strength $R_{c}$.

In carbon steel, with increasing content of carbon and surface strengthening (for example by carborating or quenching), ductility is decreased and the strength improved (Fig. 1b), changing a shape of the curve. Thus, carbon steel (soft) exhibits well-defined yield point $R_{p c}$, in case of high-carbon steel (for example $0.5 \% \mathrm{C}$, hard) offset yield strength $R_{c 0.2}$ is used, and hardened steel allows estimation of ultimate compression strength $R_{c}$. 

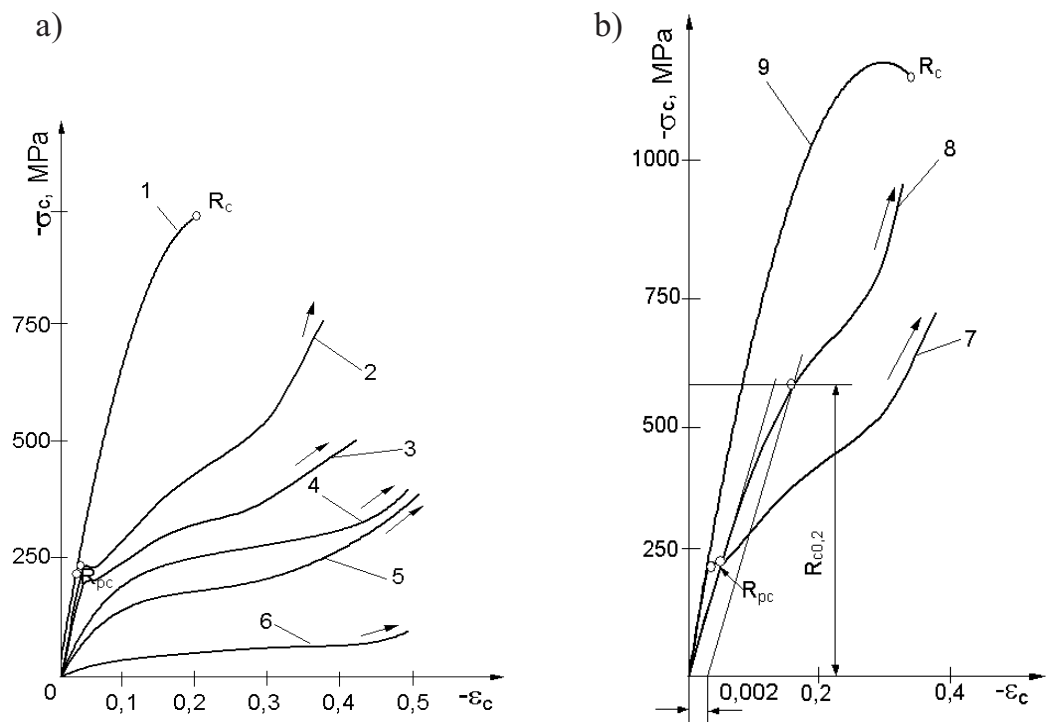

Fig. 1. Conventional diagrams of compression $-\sigma_{c}=f\left(-\varepsilon_{c}\right)$ [3]: a) different alloys: cast iron (1), carbon unalloyed (2, low-carbon), copper (3), zinc (4), aluminum (5), lead (6); b) steel: low-carbon (7), high-carbon (8) and surface carburized/hardened steel (9)

Effect of the second group of the factors can be seen in the curves from compression of copper, shown in graphs of stresses: conventional (Fig. 2a) and logarithmic (Fig. 2b). For specimens of variable slenderness $\left(h_{0} / d_{0}\right.$ ratio), it can be noted that the shorter the specimen (lower $h_{0} / d_{0}$ ratio), the higher influence of friction forces and forces arising from resistance of deformation resultant from mutual interaction of stresses, which come from the action of adjacent compression plates, varying throughout the height of the specimen. To reduce this phenomenon, the plates are lubricated. Hence, for lower slenderness ratio, higher flow stress and both conventional and true stresses are observed during upsetting. With an increase of slenderness of a specimen the effect both of friction - to a degree, and deformation resistance - in more significant extent is diminishing, and so the flow stress during compression is lower. The latter specimens undergo, thus, more significant reduction in height $\varepsilon_{c}$ and increase in diameter $q_{c}$.
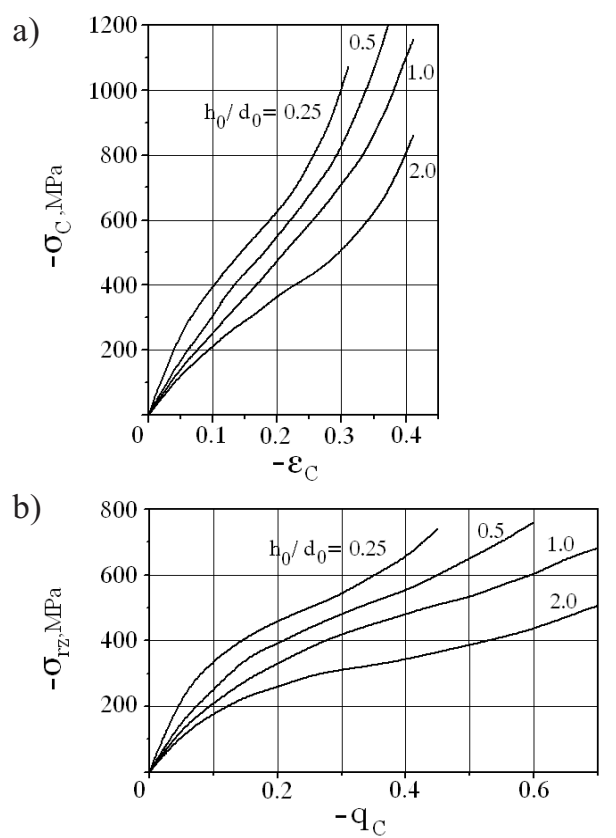

Fig. 2. Effect of aspect ratio $\left(h_{0} / d_{0}=v a r\right)$ on the shape of compression diagrams for copper; presented in the plots of: a) conventional $-\sigma_{c}=f\left(-\varepsilon_{c}\right)$; b) true $-\sigma_{r z}=f\left(-q_{c}\right)$ stresses [4] 
To obtain equal height reduction $\varepsilon_{c}$ or spread $q_{c}$ in upsetting process, with decreasing $h_{0} / d_{0}$ ratio, higher load is necessary, which is also associated with abovementioned changes of friction forces and deformation resistance resulting in increasing flow stress. Interaction of stress zones in the bulk is inextricably associated with simultaneous effect of friction forces in the head surfaces and distribution of deformation resistance in the specimen, and thereby the magnitude of applied height reduction in upsetting.

\section{STRAIN NONUNIFORMITY IN UPSETTING}

State of stresses and strains in a cylindrical specimen during upsetting in flat dies depends mainly on friction conditions in the contact surfaces metal/die. In the upsetting process of a cylindrical billet due to action of normal stresses $\sigma_{n}$, produced by external loading, in the contact surface tangential friction stresses arise $\tau_{p}$, which are directed towards the center of the billet. The stresses, dependent on friction coefficient $\mu$, hamper lateral flow of the metal. Thus, the shape of a free surface of the billet and the curvature of the barrel depend a great deal on friction coefficient $\mu$ in the contact surface $[1,3-5]$.

a)

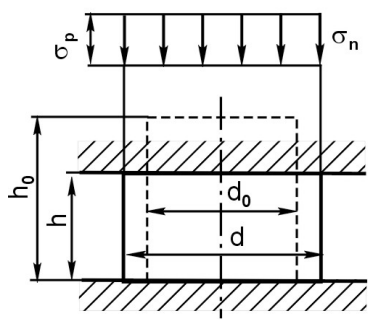

b)

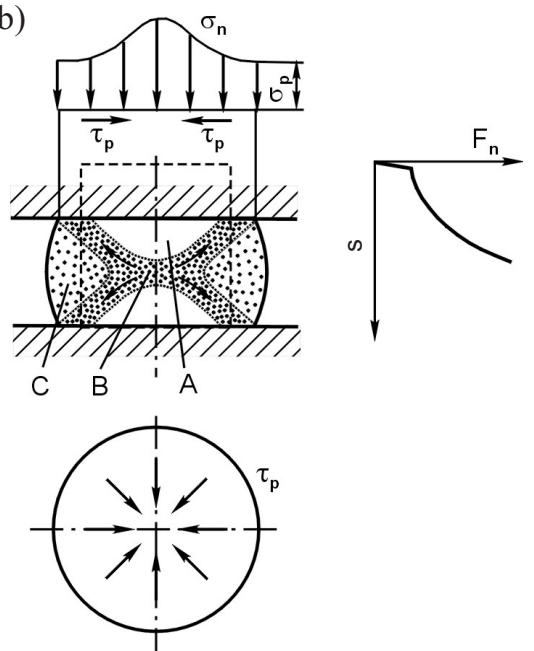

Fig. 3. Effect of friction conditions in the surface metal/tool [1] for: a) frictionless process $(\mu=0)$; b) process with friction $(\mu>0)$, in upsetting operation of cylindrical specimen in flat dies on the pattern of stresses: normal $\sigma_{n}$ and tangential $\tau_{p}$ in the contact surface and strain nonuniformity in a specimen

In upsetting in flat clean dies, when the friction coefficient has values reaching $\mu=0$, it can be assumed that the process is frictionless, and in the material linear uni-axial state of stress is arisen (Fig. 3a). Normal stress $\sigma_{n}$ (due to no resistance of deformation) equals to flow stress $\sigma_{p}$, so $\sigma_{n}=\sigma_{p}$, which allows uniform deformation in the bulk at every stage of compression.

In turn, if friction coefficient $\mu>0$, three-dimensional state of stress is produced in the material, differing in various areas of the specimen, dependent on $l_{0} / d_{0}$ ratio, which causes nonuniform deformation. During upsetting of high-slenderness billet $\left(2<h_{0} / d_{0}<2.5\right)$ in the 
middle of the height, linear state of stress is observed - this region do not undergo deformation in the beginning, and in the end zones of the billet - three dimensional state of stress, where deformed ends form double barreling under the tools.

While upsetting flat billets $\left(h_{0} / d_{0} \cong 1\right)$ in the whole volume three-axial state of stress is arisen, causing deformation of the whole of the deformed metal. In the longitudinal section of the upset-forged billet three deformation zones can be distinguished (Fig. 3b). Zone A adjacent to flat surfaces of the tools, undergo the least deformation due to the friction forces action in the surfaces of the tools, which hamper lateral flow of the material. The largest deformations, both in axial and radial directions, are found in zone B, however, there are no distinct border between them, with smooth transition to one another. Zone $\mathrm{C}$ is the area of intermediate deformation. The area of the zones depends on reduction exerted.

Nonuniformity of deformation during upsetting adversely affect the quality od the part. While cold upsetting the metal attain nonuniform hardening, and in hot upsetting recrystallized grains differ in size, leading to nonuniform mechanical and operational properties in a forged part. The nonuniformity also results in lower ductility and restriction of possible reduction for a number of materials.

\section{NUMERICAL ESTIMATION OF STRAIN NONUNIFORMITY DURING UPSETTING}

\subsection{Boundary conditions}

In industrial practice changes in strain distribution depends on tool temperature and lubricant characteristics, which is taken into consideration in assumed boundary conditions. In simulation two different materials were used, that is steel 20 (flow curve shown in Fig. 4) and electrolytic copper (flow curves in Fig. 5) [6, 7].

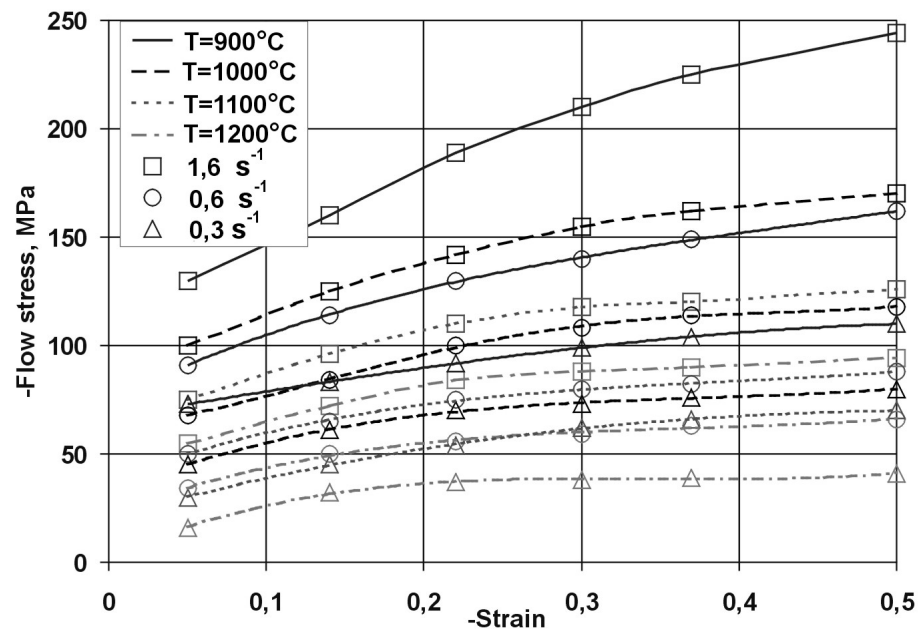

Fig. 4. Effect of: temperature $\left(T_{i}=900,1000,1100\right.$ and $\left.1200^{\circ} \mathrm{C}\right)$, rate $\left(\dot{\varepsilon}_{i}=0.3 ; 0.6\right.$ i $\left.1.6 \mathrm{~s}^{-1}\right)$ and degree $\left(\varepsilon_{i}=0-0.5\right)$ of deformation on true compression diagrams for steel 20 [6] 


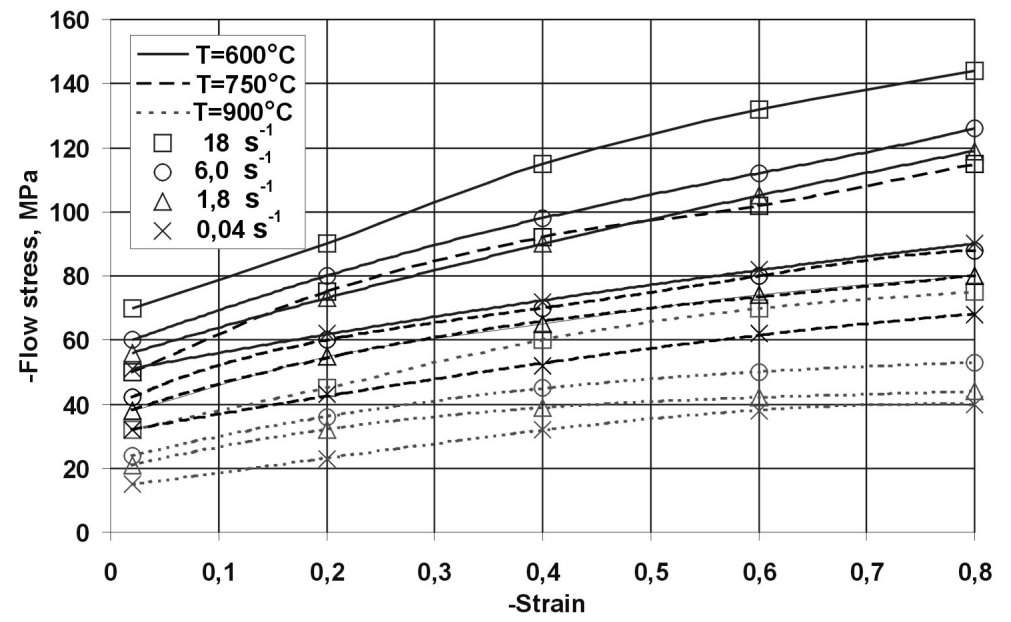

Fig. 5. Effect of: temperature $\left(T_{i}=600,750\right.$ and $\left.900^{\circ} \mathrm{C}\right)$, rate $\left(\dot{\varepsilon}_{i}=0.04 ; 1.8 ; 6.0\right.$ i $\left.18 \mathrm{~s}^{-1}\right)$ and degree $\left(\varepsilon_{i}=0-0.8\right)$ of deformation on true compression diagrams for copper Cu99,9E [6]

In the simulation, carried out with a commercial code QForm2D/3D forging workpiece with diameter $30 \mathrm{~mm}$ and height $60 \mathrm{~mm}$ (constant aspect ratio $h_{0} / d_{0}=2.0$ ) was used, made of materials similar in plasticity and strength, but different heat transfer characteristics (Tab. 1):

- copper Cu99,9E - soft material o high plasticity, mean strength and high heat transfer coefficients,

- steel 20, (carbon steel) - material of relatively good plasticity, high strength and average heat transfer characteristics.

Table 1. Thermo physical characteristics of materials measured, for room temperature, assumed in numerical calculation of the upsetting process [2]

\begin{tabular}{|l|c|c|c||}
\hline \multicolumn{1}{|c|}{ Parameter } & Unit & $\begin{array}{c}\mathrm{Cu} 99,9 \mathrm{E}^{*} \\
(99.90 \% \mathrm{Cu})\end{array}$ & $\begin{array}{c}\text { Steel 20 } \\
(0.2 \% \mathrm{C})\end{array}$ \\
\hline Ultimate strength $R_{m}$ & $\mathrm{MPa}$ & $150-240$ & $460-560$ \\
\hline Yield strength $R_{e}$ & $\mathrm{MPa}$ & 80 & 280 \\
\hline Elongation $A_{5}$ & $\%$ & 45 & 23 \\
\hline Friction factor $m$ & - & 0.30 & 0.40 \\
\hline Friction coefficient $\mu$ & - & 0.17 & 0.23 \\
\hline Thermal conductivity $\lambda$ & $\mathrm{W} /(\mathrm{m} \mathrm{K})$ & 420 & 45.5 \\
\hline Specific heat $c$ & $\mathrm{~J} /(\mathrm{kg} \mathrm{K})$ & 250 & 549 \\
\hline Heat transfer coefficient $\alpha$ & $\mathrm{W} /\left(\mathrm{m}^{2} \mathrm{~K}\right)$ & 450 & 300 \\
\hline${ }^{*}-$ annealed & & \\
\hline
\end{tabular}


The specimens were subjected to three-stages upsetting with relatively height reduction $\varepsilon_{r h i}$, ranging from $\varepsilon_{r h 0}=0 \%$ - in the beginning of the process, by $\varepsilon_{r h 10}=-16,7 \%-$ after 10 records, $\varepsilon_{r h 20}=-33,4 \%$ - after 20 records, to $\varepsilon_{r h 30}=-50,0 \%$ - after 30 records, where logarithmic deformation on total height reduction $\varepsilon_{t h i}$ changed from $\varepsilon_{t h 0}=0$, by $\varepsilon_{t h 10}=-0,182$ and $\varepsilon_{t h 20}=-0,405$ to $\varepsilon_{t h 30}=-0,693$. As far as temperature is concerned, for steel 20 temperature of $1200^{\circ} \mathrm{C}$ and for copper $900^{\circ} \mathrm{C}$ were assumed. Constant velocity of a ram was assumed equal $v_{h}=10 \mathrm{~mm} / \mathrm{s}$, at a stroke height changing from $h_{0}=60 \mathrm{~mm}$ to $h_{30}=30 \mathrm{~mm}$ in $30 \mathrm{sub}-$ sequent records, which means that in a single record actual displacement was $\Delta h_{k}=1 \mathrm{~mm}$.

On account of round cross section of the billet, axi-symmetrical state of deformation was assumed, however, the post-processor of QForm allowed three-dimensional visualization of the results in the whole section. Changes of the profile of the free surface and rectangular coordinate grid of deformations, as well as effective strain distribution in the cross section of the deformed billet are presented (after 20 records - second phase) for both of the analysed materials (Figs. 6 and 7). However, the results make it possible to investigate and conclude changes in the metal flow and strain distribution in subsequent phases of the process.

a)

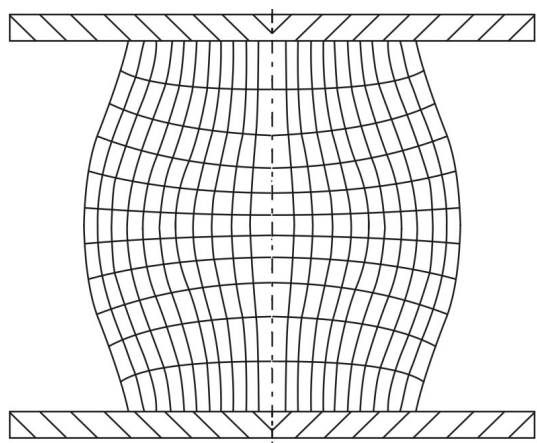

b)

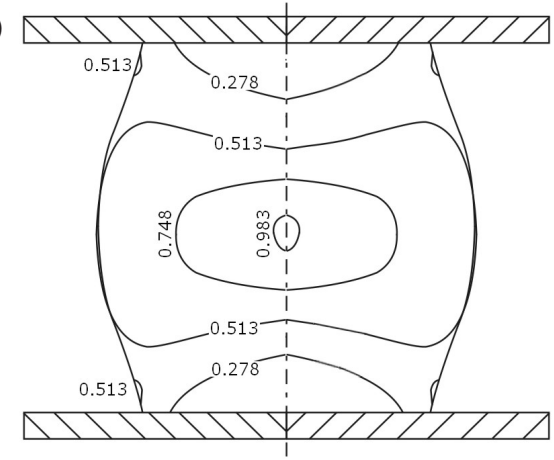

Fig. 6. Distortion of rectangular coordinate grid of deformations (a) and effective strain distribution $\varepsilon_{i}(b)$ in the cross-section of cylindrical specimen made of copper Cu99,9E, numerically calculated with a code $Q F$ orm $2 D / 3 D$ for total height reduction $\varepsilon_{\text {th } 20}=-0.405$ a)

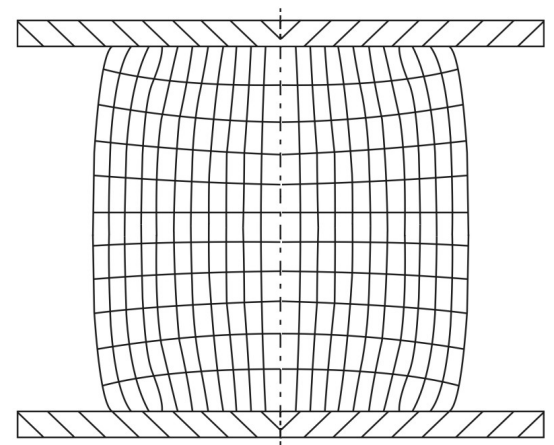

b)

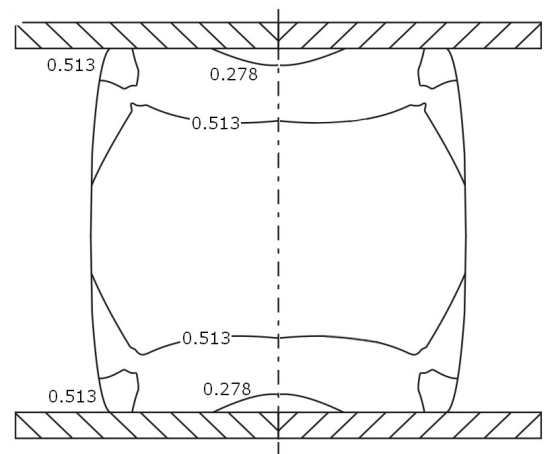

Fig. 7. Distortion of rectangular coordinate grid of deformations (a) and effective strain distribution $\varepsilon_{i}(b)$ in the cross-section of cylindrical specimen made of steel 20, numerically calculated with a code QForm $2 D / 3 D$ for total height reduction $\varepsilon_{\text {th } 20}=-0.405$ 


\subsection{Distortion of rectangular grid}

The results of the numerical modelling showing dependence of strain distribution, reperesented by distortion of rectangular grid of deformation, on the reduction in height $\varepsilon_{h i}$ (with the same friction conditions) is presented in Figure 8. The distributions are symmetrical in relation to horizontal plane, set in the half of the distance between tools, and vertical axis of rotational symmetry of deformed specimen.

a)

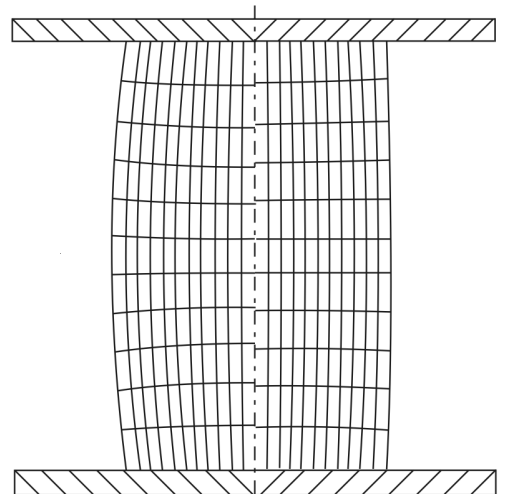

b)

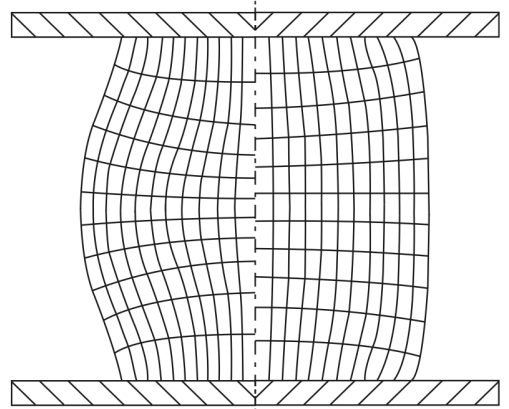

c)

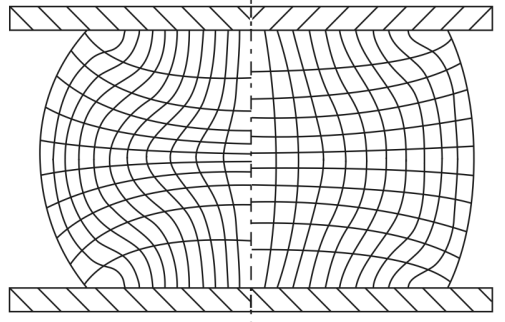

Fig. 8. Effect of unit total height reduction during upsetting: a) $\left.\varepsilon_{\text {th } 10}=-0.182 ; b\right) \varepsilon_{t h 20}=-0.405$; c) $\varepsilon_{\text {th } 30}=-0.693$ strain nonuniformity illustrated with distortion of rectangular grid of deformations in the cross-section of cylindrical specimen made of copper Cu99,9E (in the left) and steel 20 (in the right) a)

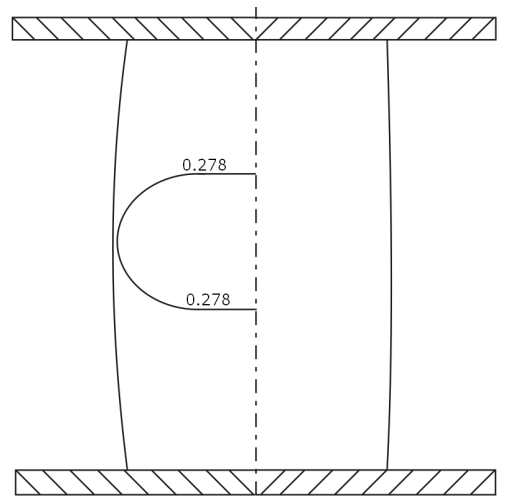

b)

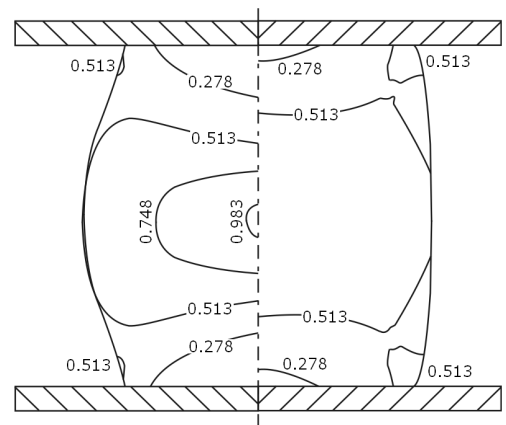

c)

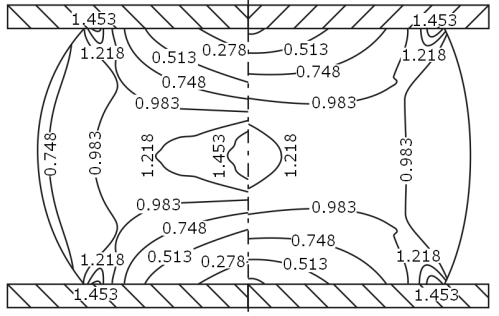

Fig. 9. Effect of unit total height reduction during upsetting: a) $\varepsilon_{\text {th } 10}=-0.182$; b) $\varepsilon_{\text {th } 20}=-0.405$; c) $\varepsilon_{\text {th } 30}=-0.693$ strain nonuniformity illustrated with effective strain distribution in the cross-section of cylindrical specimen made of copper Cu99,9E (in the left) and steel 20 (in the right) 
Consecutive deformations of the rectangular grid with increasing reduction in height $\varepsilon_{h i}$ (Fig. 8) inform that stresses more easily get into the softer material (more ductile and medium strength material). It can be observed on the strength of changes in the plastic deformations during upsetting, disclosed both by the distortion of rectangular grid in the cross section of the specimen and the profile of the free surface.

Analysis of profile of the free surface and distortion of the rectangular grid both of soft and hard material it can be clearly visible that in the whole volume areas of nonuniform deformation can be found on axial and radial direction. The least deformations are located in the areas in contact with the surface of the tools, where they are maximal hampered by friction forces. Intermediate strains of average level are found in the peripheral regions of the cross section. The largest strains are observed in the central zone of the specimen, where the action of friction forces is significantly limited and the flow of the metal is conditioned by its cohesion forces. The degree of these changes to occur increases with the deduction $\varepsilon_{h i}$.

\subsection{Effective strain distribution}

Consecutive changes of effective strain distribution $\varepsilon_{\mathrm{i}}$ with increasing reduction in height $\varepsilon_{h i}$ (Fig. 9) inform that it is more difficult for the stress to promote into the interior of the material referred as harder, that is material of lower plasticity and higher strength. It can be observed in the following stages of upsetting of the material harder-to-deformation in the range of smaller strains.

The observed changes, in accordance with the magnitude of unit relatively reduction in height, are as follows:

a) for $\varepsilon_{r h 10}=-16.7 \%$ - the hard material is in the range of small (almost uni-axial) plastic deformation (effective strain no higher $\varepsilon_{i}=0.044$ were reported in the cross section) and in softer material subjected to even higher plastic deformation, maximum effective strain reaches the value as low as $\varepsilon_{i}=0.278$, located symmetrically in relation to the tools' surface;

b) for $\varepsilon_{r h 20}=-33.4 \%$ - both soft and hard material are in the range of plastic deformations, however effective strain level in the hard material is lower, reaching $\varepsilon_{i}=0.278$ and 0.513 , while the central zones are still not deformed, and in the soft material from $\varepsilon_{i}=0.278-$ under the tools, to $\varepsilon_{i}=0.983$ - maximum located in the middle of the specimen;

c) for $\varepsilon_{r h 30}=-50.0 \%$ - effective strain is different in the whole volume of the specimens, since:

- in the harder material is higher right beneath the plate (tool) and insignificantly lower in the center, reaching $\varepsilon_{i}=0.278$ - in the undersurface region beneath the tool, to $\varepsilon_{i}=1.218$ - in the center, increasing to $\varepsilon_{i}=1.453$ - in the peripheries of the zones under the tools;

- in the softer material is insignificantly lower under the plates and slightly higher in the axis of the specimen, ranging from $\varepsilon_{i}=0.278-$ in the axis of the specimen right under the tool, to $\varepsilon_{i}=1.453-$ in the center of the specimen, reaching $\varepsilon_{i}=1.218-$ in the peripheries at the contact surface (cold ends);

- for both materials shapes of effective strain isolines are different, however symmetrical in relation to the plane of plates. 


\subsection{The load during upsetting}

The upsetting load $F_{n}$ is affected by factors which influence the process of strengthening of a given metal, strongly connected with thermo-mechanical conditions of the deformation process. Generally, they determine so called dependence of the material on changes in temperature and degree and rate of strain. An important part to resistance of the metal flow contribute other factors, such as friction factor and the efficiency of lubrication techniques. Numerically calculated plots of the forging load $F_{n}$ during upsetting of the analyzed metals are shown in Figure 10.

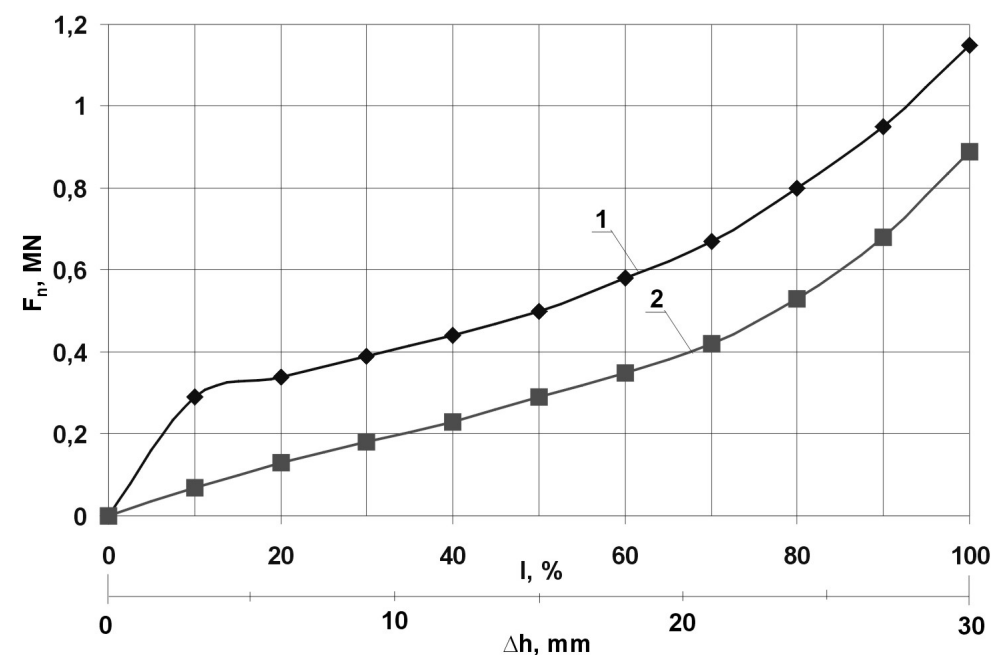

Fig. 10. Plots of upsetting load $F_{n}$ for different relatively height reduction $\varepsilon_{r h i}$ in upsetting of specimens made of: 1 - steel 20, 2 - copper Cu99,9E

The observed course of changes of load $F_{n}$ during upsetting results from simultaneous effect of strengthening and action of friction forces in the contact surface metal-tool and in adjacent zones, reflected also by profile of the free surface, which for the softer metal is more distorted (insignificant lateral flow in the area of the contact surface metal-tool and bigger in the middle of the height), whereas for the harder one it is less curved (more significant lateral flow in the ends compared to the middle of the height. Such a tendency is maintained during the whole increasing height reduction $\Delta h$ during upsetting, as in the beginning of the process, for $\varepsilon_{h 0}=0 \%-d_{0 \mathrm{Cu}}=30.0 \mathrm{~mm}$ and $d_{0 \mathrm{St}}=30.0 \mathrm{~mm}$; and with the increase of the reduction the diameters increase respectively, as for $\varepsilon_{r h 10}=-16.7 \%-d_{10 \mathrm{Cu}}=$ $=35.0 \mathrm{~mm}$ and $d_{10 \mathrm{St}}=36.7 \mathrm{~mm}$; for $\varepsilon_{r h 20}=-33.4 \%-d_{20 \mathrm{Cu}}=39.9 \mathrm{~mm}$ and $d_{20 \mathrm{St}}=43.2 \mathrm{~mm}$; for $\varepsilon_{r h 30}=-50.0 \%-d_{30 \mathrm{Cu}}=57.6 \mathrm{~mm}$ and $d_{30 \mathrm{St}}=63.2 \mathrm{~mm}$.

\section{SUMMARY AND CONCLUSIONS}

On the basis of the upsetting operation, analysis of some cases of its industrial application was made. Next to this, the plots of compression curves were analysed. It was con- 
cluded that their shapes depend on many technological parameters of the upsetting process, such as: mechanical properties (including plasticity and rheological properties); slenderness of a billet, that is $h_{0} / d_{0}$ ratio (where: $h_{0}, d_{0}$ - initial height and diameter of deformed billet); friction coefficient in the contact surface metal/tool; degree of deformation - reduction in height of the billet.

In the first part strain distribution in materials, such as electrolytic copper $\mathrm{Cu} 99,9 \mathrm{E}$, commonly referred to as soft material, or materials regarded as relatively hard materials with an example of steel 20 , containing $0,2 \% \mathrm{C}$, observed during upsetting of these materials was investigated. Numerical calculations, performed with a code QForm2D/3D showed significant influence of friction forces in the metal/tool interface on changes of the profile of the free surface of deformed billet, as well as on distortion of the rectangular grid of coordinates and effective strain distribution in the cross-section of the specimen in consecutive stages of the upsetting process. These results allow to conclude inhomogeneous distribution of mechanical properties of forgings.

The presented studies prove that estimation of a forging diameter based on constant volume equation (eq. (1)) results in large discrepancies from real values, which is attributed to nonuniformity of deformation in the volume of upset forged material.

\section{REFERENCES}

[1] Erbel S., Kuczyński K., Marciniak Z.: Obróbka plastyczna. PWN, Warszawa, 1981

[2] Dobrzański L.A.: Zasady doboru materiałów inżynierskich z kartami charakterystyk. Wyd. Politechniki Śląskiej, Gliwice, 2000

[3] Katarzyński S., Kocańda S., Zakrzewski M.: Badania własności mechanicznych metali. WNT, Warszawa, 1967

[4] Madej J., Kazanecki J., Wnęk Z.: Ćwiczenia laboratoryjne z przeróbki plastycznej metali. Wyd. AGH, Kraków, 1971 (skrypt uczelniany nr 220)

[5] Sińczak J. i in.: Procesy przeróbki plastycznej. Wyd. Nauk. AKAPIT, Kraków, 2003

[6] Biba N., Stebounov S., Lishiniy A.: Cost effective implementation of forging simulation. Journal of Materials Processing Technology, 113 (2001), 34-39

[7] Piqtkowski P., Kukuryk B.: Analiza technologii kucia swobodnego z wykorzystaniem makroskopowych efektów mikropasm ścinania. Rudy i Metale Nieżelazne, 50 (2005) 10-11, 576-579 